\title{
ENVELHECER COM DEFICIÊNCIA INTELECTUAL: MEMÓRIAS DE UMA MÃE SOBRE SEU FILHO IDOSO COM DEFICIÊNCIA INTELECTUAL
}

\author{
GIMENES, Priscila Alvarenga Cardoso ${ }^{1}$ \\ DENARI, Fátima Elisabeth ${ }^{2}$
}

Recebido em: 2017.08.31

Aprovado em: 2019.04.29

ISSUE DOI: $10.3738 / 1982.2278 .2856$

\begin{abstract}
RESUMO: Nas últimas décadas tem-se observado aumento na expectativa de vida de pessoas com deficiência intelectual, o que vem despertando, em alguns setores da sociedade, interesse para com a atenção ao processo de envelhecimento destas pessoas, bem como para a estruturação de serviços que atendam a esta demanda. Objetivando contribuir com os estudos sobre as peculiaridades desta população, a presente pesquisa visou compreender como uma mãe vivencia o processo de envelhecimento de seu filho, ressaltando as possibilidades e dificuldades enfrentadas e sua percepção sobre o processo de envelhecimento das pessoas com deficiências, sobretudo intelectual, na sociedade atual. Para tanto, foi utilizada uma abordagem qualitativa, tendo como embasamento teórico o entendimento fenomenológico, pautado no método de história de vida e contando com uma entrevista aberta. Tal pesquisa mostrouse relevante devido à apresentação de várias questões e aspectos relacionados ao processo de envelhecimento das pessoas com deficiência, enfocando principalmente a fragilidade das famílias idosas em cuidar de um filho com deficiência intelectual que também vivencia a velhice e a necessidade de se implantar serviços específicos de atendimento a esta demanda.
\end{abstract}

Palavras-chave: Deficiência intelectual. Envelhecimento. Família.

SUMMARY: In recent decades, an increase in the life expectancy of people with intellectual disabilities has been observed, which has been generating, in some sectors of society, special interest in their aging process and in structuring services that meet this demand. Aiming to contribute to studies on the peculiaritie of such population, the present research was thought to comprehend how a mother experiences the ageing process of her child in current society, highlighting its possible achievements and difficulties and her perception of disabled people's ageing process, particularly in the intelectual field. Thus, a qualitative approach was used, having the phenomenological understanding as theoretical basis, founded on the life-history method and featuring an open interview. This research was relevant due to the presentation of various issues and aspects related to the ageing process of people with disabilities. The main focus was on elderly families taking care of an intellectual disabled child who also experiences old age, in the light of their fragile situation and the urge to implement such specific services.

Keywords: Intellectual disability. Aging. Family

\section{INTRODUÇÃO}

Atualmente, em diversas cidades do país já é possível localizar pessoas com deficiência intelectual vivenciando a velhice, alguns com 60 anos ou mais e outros que ainda não tendo atingido esta idade, manifestam as características desta fase da vida tanto nos aspectos físicos quanto sociais e emocionais.

Este fenômeno é resultado, entre outros fatores, das mudanças na forma como a sociedade se relaciona com as pessoas com deficiência intelectual permitindo, ao longo das últimas décadas, maior visibilidade e consequentemente ampliação nas possibilidades de participação social, oferta de atendimentos nas áreas sociais, educacionais e médicas e acesso a tratamentos que tem prolongado a vida destas pessoas. A este respeito Flórez (2000) pontua que esta ocorrência se deve principalmente aos

\footnotetext{
${ }^{1}$ Universidade Federal de São Carlos - Faculdade de Filosofia, Ciências e letras de Ituverava

${ }^{2}$ Universidade Federal de São Carlos
} 
Avanços na medicina, à oferta de vacinas e tratamentos específicos, aos cuidados dispensados a estas pessoas e à melhoria das condições de alimentação, higiene e saneamento básico.

Esta nova postura frente às pessoas com deficiência intelectual tem possibilitado que muitas delas que até meados do século XX raramente ultrapassavam os trinta anos, atualmente alcancem a velhice e apresentem expectativa de vida acima dos cinquenta anos.

Entretanto a possibilidade de envelhecer desencadeia uma série de novos desafios e reflexões. Tanto para as famílias das pessoas com deficiência, sobretudo os pais ou parentes próximos, que também vivenciam o envelhecimento e nem sempre detém condições financeiras e físicas para assegurar a elas os cuidados necessários, como ressalta Breitenbach (2001, on line): "[...] freqüentemente os pais e os filhos adultos estão envelhecendo lado a lado. Estamos descobrindo famílias nas quais o cabelo "do filho" é grisalho e o do pai (pais) é branco como a neve.".. Quanto para os gestores de políticas públicas e para a sociedade em geral, visto que são necessários atendimentos específicos que possibilitem melhores condições de vida ao longo da idade adulta e apoio diferenciado na velhice.

Esta situação pode ser entendida, em muitos casos, pelo que os autores denominam de dupla exclusão, pois como apresenta Marin, et al. (2013), as pessoas com deficiência em processo de envelhecimento convivem com as limitações impostas tanto pela deficiência, quanto pelo envelhecimento. Os autores também ressaltam que a maior parte das pessoas que não apresenta deficiência constrói, ao longo da vida, uma rede de relacionamentos, dentre elas os familiares como filhos, netos que comumente auxiliam no processo de envelhecimento, o mesmo, geralmente não ocorre com as pessoas com deficiência intelectual.

Contribuindo para o agravamento desta situação de envelhecimento e maior vulnerabilidade da pessoa adulta com deficiência intelectual, estão a falta de serviços especializados e de programas que atendam a esta população, que na maior parte dos casos também sofre com a falta de recursos financeiros e ausência ou escassez de relacionamentos sociais, dificultando a vivência da velhice com dignidade. Siqueira e Neri (2011, p.255) apontam que: "Em comparação com a população geral, os portadores de deficiência mental contam com menos possibilidades de acesso aos serviços de saúde e têm mais dificuldades em relatar suas queixas, em decorrência das dificuldades de comunicação". Também alertam para o fato de que o deficiente intelectual ainda apresenta maior probabilidade de adotar estilos de vida e hábitos prejudiciais, tais como: "[...] o sedentarismo e o comportamento sexual de risco e estão mais expostos ao abuso sexual e ao consumo de substâncias nocivas como o tabaco e as drogas" (SIQUEIRA; NERI, 2011, p.255).

Por tratar-se de um fenômeno recente, ainda há poucos estudos científicos a respeito do processo de envelhecimento das pessoas com deficiência intelectual e das relações estabelecidas com seu cuidadores. Considerando a relevância da construção de conhecimentos sobre esta temática para subsidiar a elaboração e execução de políticas públicas voltadas a esta população e a oferta de atendimentos específicos, a presente pesquisa teve como objetivo compreender e apresentar informações sobre como uma mãe vivencia o processo de envelhecimento de seu filho, ressaltando as possibilidades e dificuldades enfrentadas e sua percepção sobre o processo de envelhecimento das pessoas com deficiências, sobretudo intelectual, na sociedade atual.

A pesquisa, de abordagem qualitativa, teve como embasamento teórico o entendimento fenomenológico, pautada no método de história de vida e realizada a partir de uma entrevista aberta junto a Maria Amélia Vampré Xavier, que é uma das fundadoras da Associação de Pais e Amigos dos Excepcionais - APAE de São Paulo e mãe de Ricardo que possuía deficiência intelectual e faleceu poucos meses antes de completar 60 anos. 
A realização desta pesquisa possibilitou refletir sobre vários aspectos imbricados no processo de envelhecimento das pessoas com deficiência intelectual, tanto no que se refere às peculiaridades da pessoa que envelhece quanto aos desafios enfrentados por seus familiares, ressaltando a fragilidade dos pais em assumir os cuidados para com o filho idoso.

\section{MÉTODO:}

A presente pesquisa se fundamenta em uma abordagem qualitativa, buscando apreender a compreensão, a percepção e os sentimentos da mãe de uma pessoa com deficiência intelectual que chegou à velhice.

Tem como embasamento teórico os pressupostos da fenomenologia de Merleau-Ponty, por meio do qual se busca descrever o fenômeno observado, ou seja, o relato apresentado pelo sujeito, em sua essência, sem a intenção de explicá-lo, mas de identificar a percepção e os significados construídos a partir de sua experiência no mundo vivido, pois como pontua o autor: "Trata-se de descrever, e não de explicar nem analisar [...] Tudo o que sei do mundo, mesmo devido à ciência, o sei a partir de minha visão pessoal ou de uma experiência do mundo sem a qual os símbolos da ciência nada significariam" (MERLEAUPONTY, 1994, Prefácio, p.II).

A pesquisa foi realizada de acordo com as orientações do comitê de ética, sendo que a divulgação da identidade da participante foi previamente autorizada e o texto avaliado e também por ela autorizado ${ }^{3}$.

\section{Participante:}

Maria Amélia Vampré Xavier foi escolhida para participar desta pesquisa por ser mãe de uma pessoa com deficiência intelectual que alcançou a velhice, por se tratar de uma pessoa com forte engajamento na luta por melhores condições de vida para pessoas com deficiência, sendo uma das fundadoras da APAE de São Paulo. Pessoa de reconhecido mundial, autora de livros, de diversos artigos e tradutora de materiais relacionados à inclusão social da pessoa com deficiência, por ter atuado em diversas organizações e projetos em prol de melhores condições de vida das pessoas com deficiência. E principalmente por escrever e traduzir vários textos que discorrem sobre o processo de envelhecimento das pessoas com deficiência e seus familiares, tais como: Tenho um filho deficiente que está envelhecendo, e agora? (XAVIER, 2010), Como poder ajudar, de fato, as pessoas da família (a maioria esmagadora mulheres) que cuidam do filho que está envelhecendo com os pais? (XAVIER, 2014), o livro Enfrentando desafios: envelhecimento e deficiência (XAVIER, 2015), entre outros.

\section{Instrumentos para a coleta de dados}

A pesquisa de campo teve como referência o método de história oral de vida e foi realizada por meio de uma entrevista livre com Maria Amélia Vampré Xavier, visto que este instrumento atende ao propósito desta pesquisa que está pautada em um entendimento fenomenológico dos fatos. Pois ao oferecer à mãe de uma pessoa com deficiência que alcançou a velhice a oportunidade de relatar livremente sua experiência em acompanhar o processo de envelhecimento do filho, buscou-se descrever seus sentimentos, angústias, medos e sua percepção sobre o processo de envelhecimento das pessoas com deficiências na sociedade atual. Para Tinós (2010, p.37) "O que é relevante neste processo é ouvir compreensivamente quem vivencia o mesmo". Alberti (2013, p. 24) caracteriza o método de história oral como "[...] um método de pesquisa que privilegia a realização de entrevistas com pessoas que participaram de, ou testemunharam, acontecimentos, conjunturas, visões de mundo, como forma de se

\footnotetext{
${ }^{3}$ Pesquisa autorizada pelo Comitê de Ética em pesquisas sob o CAAE: 35830614.1.0000.5504.
} 
aproximar do objeto de estudo".

Nas pesquisas pautadas no método de história de vida, são utilizadas entrevistas abertas que devem ser realizadas de forma menos sistematizadas, pois como argumentam Glat, et al, (2004, p. 237): "O método de Historia de Vida, consiste em uma entrevista aberta, isto é, sem um roteiro pré-determinado, na qual se pede ao sujeito para falar livremente sobre sua vida, um determinado período ou aspecto dela".

Para Alberti (2013) a entrevista exerce papel central ao se realizar um trabalho com a história oral, assim, esta deve ser objeto de todo cuidado e dedicação por parte dos pesquisadores. Neste sentido um aspecto de fundamental importância, de acordo com Rojas (1999), é a interação do pesquisador e o sujeito, visto que esta será determinante para que o narrador evoque fatos de sua memória e compartilhe com o pesquisador. Ainda de acordo com Alberti (2013, p.30-31):

A entrevista de história oral permite também recuperar aquilo que não encontramos em documentos de outra natureza: acontecimentos pouco esclarecidos ou nunca evocados, experiências pessoais, impressões particulares etc. [...] O processo de recordação de algum acontecimento ou alguma impressão varia de pessoa para pessoa, conforme a importância que se imprime a esse acontecimento no momento em que ocorre e no(s) momento(s) em que é recordado.

Ao buscar a história de vida de uma pessoa, tem-se o objetivo de garimpar memórias, de encadear fatos, de dar sentidos a experiências, pois como apontam Simson e Giglio (2012, p. 131): "Um domínio que os mais velhos podem, de fato, destacar-se, graças ao acúmulo de informações e experiências é o de narrar, interpretar o passado, bem como analisar o presente à luz as experiência pregressa".

Ao propor que sejam ressaltadas memórias e lembranças, fica evidente que não se busca a reconstrução exata dos fatos, mas sim, apreender e compreender a visão do sujeito sobre suas experiências, sobre o vivido e os sentimentos latentes em cada relato. De acordo com Rojas (1999), as lembranças permitem que a história seja pensada, debatida, construída e transformada, na medida em que converte as memórias e as lembranças em experiências sociais.

\section{Procedimentos de coleta de dados:}

Meihy (2005) discorre que o processo de coleta de dados em pesquisas que envolvem a história oral de vida é dividido em três momentos sendo: pré-entrevista que consiste na realização dos primeiros contatos e a aproximação do pesquisador com o sujeito e com o contexto; a entrevista propriamente que deve ser caracterizada por um ambiente afável, possibilitando que a pessoa possa narrar sua história sem constrangimentos, e a pós-entrevista, que é o trabalho do pesquisador em organizar e realizar o tratamento da entrevista.

Atendendo à metodologia proposta por Meihy (2005), a pré-entrevista consistiu na realização de contatos telefônicos e troca de mensagens eletrônicas que possibilitaram a aproximação da pesquisadora com a entrevistada e agendamento do encontro para entrevista que ocorreu na residência da entrevistada. Além do levantamento de diversos materiais produzidos e traduzidos por Maria Amélia Vampré Xavier, bem como de notícias e informações disponíveis na internet relacionados à sua atuação marcante na luta por melhores possibilidades de atendimentos, tratamentos e participação social das pessoas com deficiência intelectual, e a leitura de seus livros: Do outro lado do arco-íris: meu filho Ricardo (XAVIER, 1984), em que narra sua história desde o nascimento de seu filho até a década de 80 e Enfrentando o desafio: deficiência e envelhecimento (XAVIER, 2015) em que apresenta os desafios enfrentados pelas famílias das pessoas com deficiência em lidar com o processo de envelhecimento de seus filhos.

$\mathrm{Na}$ sequência foi realizada a entrevista que durou aproximadamente uma hora e quarenta minutos, foi gravada digitalmente e teve início com a solicitação de que a participante apresentasse aspectos 
relevantes sobre o desenvolvimento do filho com deficiência e seu processo de envelhecimento, com destaque para os desafios enfrentados, as dificuldades e possibilidades de atendimento, seus sentimentos, angústias, medos, sua percepção sobre o processo de envelhecimento das pessoas com deficiências na sociedade atual, bem como sobre os atendimentos disponibilizados a esta população. A entrevistada mostrou-se muito a vontade e feliz com a possibilidade de participar da pesquisa.

A recepção da participante, sua disponibilidade e contentamento confirmam o que Simson e Giglio (2012) pontuam:

Do ponto de vista psíquico, afetivo, emocional, a pessoa que envelhece só poderá ter a noção de que as informações de que dispõe são preciosas, e não um fardo inútil, se seu meio social se interessar por elas, ou seja, se as acolher como interessantes ou úteis. [...] quando um membro da comunidade é selecionado por pesquisadores da universidade para registrar sua história de vida para posterior trabalho de pesquisa, seu status no círculo familiar e na comunidade local é significativamente reforçado. (SIMSON; GIGLIO, 2012, p. 144)

As autoras supracitadas salientam ainda que ao valorizar a narrativa do idoso, este assume o lugar daquele que sabe, que detém um bem valioso para compartilhar. Neste sentido, foi de grande relevância possibilitar que Maria Amélia Vampré Xavier, apresentasse alguns fragmentos de sua trajetória, suas principais memórias, a fim de que estas sejam realçadas e valorizadas e que possam lançar luz sobre as ações desenvolvidas atualmente em prol das pessoas com deficiência e de seus familiares.

A entrevista transcorreu tranquilamente e a participante, de modo muito agradável, como uma avó contando histórias, narrou diversos fatos, emocionou-se em alguns momentos e reconstruiu, a sua maneira, aspectos relevantes da vida de seu filho e dos impactos em sua vida. Ao oportunizar que apresente sua história de vida, a ela foi dada a possibilidade de mostrar ou esconder fatos, lembranças, memórias, enfim, apresentar a história sob sua perspectiva e intencionalidade. Alguns acontecimentos citados ao longo da entrevista já haviam sido narrados em seus livros.

\section{Procedimentos de análise dos dados:}

A entrevista foi transcrita e as informações foram organizadas em categorias, de acordo com os assuntos abordados, sem que houvesse preocupação em analisar as informações, visto que esta pesquisa utiliza-se da perspectiva fenomenológica sob a qual o fenômeno é descrito e a partir da forma como é sentido, pois de acordo com Rezende (1990, p.17) "A preocupação da fenomenologia é dizer em que sentido, há sentido, e mesmo em que sentido há sentidos. Mais ainda, nos fazer perceber que há sempre mais sentido além de tudo aquilo que podemos dizer."

Ainda de acordo com Rezende (1990, p.27) "A fenomenologia busca a compreensão, embora com a certeza de nunca a alcançar em seu sentido pleno" e acrescenta que: "[...] tanto a descrição quanto a compreensão implicam, por sua vez, a interpretação, a hermenêutica, como sendo a atitude que de fato corresponde a busca da verdade: interpretar é tentar desvelar, no sentido em que o desvelamento é possível" (REZENDE, 1990, p. 29).

Desta forma, para melhor organizar a apresentação das informações fornecidas pela participante, sua fala foi descrita em tópicos, sendo que estes comportam diversos subtemas.

\section{MARIA AMÁLIA VAMPRÉ XAVIER, MÃE DO RICARDO}

Maria Amélia é uma adorável e lúcida senhora que tem orgulho em dizer que teve o privilégio de ter conhecido o Ricardo, pois se não fosse a convivência com ele, seria uma pessoa muito preocupada 
consigo. Esta valorosa constatação coincide com sua determinação em buscar melhores condições de vida para as pessoas com deficiência.

Foi com grande satisfação que Maria Amélia apresentou sua experiência como mãe de uma pessoa com deficiência que passou por vários desafios ao longo da vida e vivenciou as peculiaridades da velhice. Narrou diversos fatos que marcaram sua vida e a vida de seu filho, sendo que seu discurso foi caracterizado por grande gratidão a diversas pessoas que a auxiliaram durante a vida. Apresentou alguns fatos, anteriormente mencionados em seu livro: O outro lado do arco-íris: meu filho Ricardo (XAVIER, 1984), o que possibilitou estabelecer uma continuidade dos acontecimentos narrados no livro e também aspectos apresentados no livro: Enfrentando desafios: deficiência e envelhecimento (XAVIER 2015).

É válido ressaltar que Ricardo faleceu pouco tempo após a realização da entrevista, e que sua fala não contemplou este acontecimento.

Por ser uma entrevista livre, norteada por princípios da pesquisa com história oral, inicialmente foi apresentado à participante os objetivos da pesquisa e o que se esperava que ela abordasse. Ela iniciou apresentando a data de nascimento do Ricardo, mas em seguida mudou o assunto e quando retornou já abordou sua situação atual, "começando pelo fim", como ela disse. Entretanto para melhor apresentar as informações, assuntos e fatos expostos na entrevista, estes foram agrupados de acordo com o assunto principal abordado pela entrevistada, ou seja, em categorias apresentados a seguir:

\section{Maria Amélia}

Maria Amélia aprendeu a ler e a escrever sozinha e disse que sempre apreciou a leitura e o estudo. Formou-se no ginásio e cursou secretariado bilíngue na Universidade Mackenzie, o que foi determinante para ocupar o cargo de $1^{a}$ secretária da APAE de São Paulo, instituição da qual muito se orgulha por ter ajudado a fundar. De acordo com Mazzottta (1996, p.47), "[...] a APAE de São Paulo foi fundada no dia 4 de abril de 1961 como entidade particular, assistencial, de natureza civil, sem fins lucrativos".

Devido à sua habilidade para datilografia e domínio da língua inglesa, Maria Amélia assumiu a responsabilidade de estabelecer contato com instituições internacionais que também atendiam crianças com deficiência intelectual. Ela afirma que:

Quando nós fundamos a APAE de São Paulo, a nossa presidente dona Alda, me disse: Olha Maria Amélia eu sei muito bem Inglês e Alemão, mas não sei escrever nada a máquina, mas, se você, que é secretária bilíngue escreve para mim, nós vamos nos comunicar com o exterior, nós vamos nos comunicar com a universidade dos Estados Unidos, da Inglaterra, associação de pais de lá.

O anseio de dona Alda foi realizado e corresponderam-se com diversas instituições internacionais, Maria Amélia foi uma das grandes responsáveis por traduzir para a língua portuguesa, textos e livros em inglês. O trabalho desenvolvido por ela foi de grande relevância e possibilitou à APAE e a interessados no estudo e atendimento à pessoas com deficiência, conhecer como outros países tratavam e cuidavam desta parcela da população, que, no Brasil, em meados de 1950 começavam a buscar atendimentos, pois como afirma Jannuzzi e Caiado (2013), "Em 1954, foi criada a primeira APAE, que, entre 1954 e 1974, se expandiu para 198 unidades em 16 estados" (JANNUZZI; CAIADO, 2013, p. 4). Esta expansão deve-se principalmente a busca das famílias por atendimentos a seus filhos que apresentam deficiência.

Desta forma, a escassez de informações, no país sobre como realizar o atendimento às pessoas com deficiência, conferiu a Maria Amélia e a APAE de São Paulo o papel de buscar conhecimentos junto a instituições e a pessoas de outros países que possuíam experiências bem sucedidas, tanto relacionadas a aspectos, médicos, terapêuticos, sociais, quanto educacionais. Tal fato é confirmado por Pessotti (2012), 
que aponta Dr. Krynski, médico psiquiatra que trabalhou na APAE de São Paulo e participou da fundação da Federação Nacional das APAES, como um dos pioneiros nesta área de estudo "O estudo científico da deficiência mental no Brasil é ainda incipiente; desde a dissertação pioneira de Ulysses Pernambuco (1918) e os esforços "missionários" de Krynski (1979) e outros pesquisadores já se formam no país núcleos promissores de pesquisa e estudo" (PESSOTTI, 2012, p. 197). E Maria Amélia pontua que:

Nós fizemos amizade com duas autoridades em deficiência mental, como se dizia na época, elas nos deram uma lista de coisas, mandaram livros, e então a APAE de São Paulo ficou muito assim enriquecida com uma porção de coisas do exterior. Isso foi uma coisa importante não é?

Contatar com pessoas de outros países e traduzir textos foram atividades de grande importância na vida de Maria Amélia, que além de ter sido a responsável pelas relações internacionais da FENAPAES, traduziu textos enviados por diversas instituições internacionais..

\section{Ricardo: diagnósticos, tratamentos e escolarização:}

Ricardo nasceu em 28 de setembro de 1956 e logo após seu nascimento, foi diagnosticado com "mau desenvolvimento congênito do sistema nervoso, meningocele" (XAVIER, 1984), entretanto os demais diagnósticos foram apresentados ao longo da infância, sendo que as convulsões começaram quando ele possuía cinco meses, e permaneceram por muitos anos, apresentou atrasos no desenvolvimento motor (hipotonia músculos paravertebrais, além dos comprometimentos ocasionados pela espinha bífida) e quando ele possuía três anos, Maria Amélia recebeu o diagnóstico que encontrou maior dificuldade em aceitar, o de deficiência intelectual.

O fato de ter tido um filho com deficiência, inicialmente desencadeou em Maria Amélia e seus familiares diversos sentimentos, pois como narra em seu livro: "[...] os meus primeiros três anos após o nascimento de Ricardo foram cheios de tormento, pois, a respeito de tomar dose maciça de medicamentos, Ricardo tinha crises convulsivas diárias e frequentes" (XAVIER, 1984, p. 39). Ela aponta que viveu momentos muito difíceis, de indignação e revolta, tanto por ter uma criança com tantos comprometimentos, quanto por não poder cuidar adequadamente de seu filho mais velho, nem de seu casamento, pois os cuidados com Ricardo consumiam a maior parte de seu tempo. A este respeito Amaral (1995) afirma que:

Podemos dizer que o impacto da deficiência na família reveste-se de tonalidade muito semelhante, uma vez que os sentimentos gerados pela sua ocorrência oscilam entre polaridades muito fortes: amor e ódio, alegria e sofrimento; uma vez que as reações concomitantes oscilam entre aceitação e rejeição, euforia e depressão - para citar o que ocorre com maior frequência. (AMARAL, 1995, p. 73)

Amaral (1995) também apresenta que comumente as famílias vivenciam, como Maria Amélia, o luto pela 'morte' do filho desejado e que este processo é vivenciado de diversas formas, dependendo da história da família, do seu dinamismo, do nível socioeconômico familiar, das expectativas em relação aos filhos, do sentido atribuído a deficiência, do grau de comprometimento do filho e da forma como foi transmitido o diagnóstico.

Quanto aos diagnósticos, Maria Amélia narrou que sempre confiou nos médicos que atendiam Ricardo e estes manifestavam respeito e compaixão para com ela, porém, com pesar, contou que em uma ocasião, um médico a deixou muito abalada, pois: 
No dia do exame, a enfermeira havia faltado e o médico estava de mau humor, foi então que ele olhou para mim e disse: olha, a senhora esqueça que teve esse filho! Porque esse menino tem uma cabeça que nada funciona, ele tem uma cabeça de velho, nada dentro da cabeça dele funciona uma coisa com a outra. Olha, eu queria dizer uma coisa para vocês, tantos anos passados, quase sessenta anos, eu nunca vou esquecer. Eu me senti como se estivesse encolhendo, encolhendo, encolhendo, sabe, como se eu virasse uma formiguinha, de tão apavorada que eu fiquei.

Diferente do que aconteceu com Maria Amélia atualmente começa a existir, por parte de muitos profissionais da saúde, uma preocupação, em tornar o momento da informação aos pais menos traumático e mais humanizado, pois como afirma Barbosa; Chaud e Gomes (2008, p. 47), a notícia da deficiência de um filho pode alterar o estado emocional dos membros da família, pois esta inicia uma "batalha adaptativa para recuperar o equilíbrio, e embora somente um membro da família seja deficiente, todos os demais são afetados e, até certo ponto, incapacitados por ela". E ressaltam que:

O desamparo enfrentado pelos pais pode ser minorado se forem utilizadas maneiras mais adequadas de informar o diagnóstico de deficiência do filho. A ausência dessas condições pode aumentar as dificuldades no enfrentamento da nova situação, dado o decisivo papel da comunicação do diagnóstico, a qual marca o início de um processo de ajustamento para toda a vida da família (BARBOSA; CHAUD; GOMES, 2008, p.47)

Outro aspecto comentado por Maria Amélia, que aflige os pais de crianças com deficiência é o distanciamento da família estendida, desencadeando maior isolamento social da família, em um momento em que precisa de ajuda. Ela narra que embora sempre tenha contado com a ajuda de sua mãe, de sua sogra de alguns parentes mais próximos, e de muitas pessoas que se solidarizavam com sua situação, também sofreu com o isolamento, como apresenta:

A primeira coisa que acontece quando nasce uma criança assim (com deficiência), é que a família maior, chamada "extended family", se separa, então, supondo, os primos, irmãos que eu tinha diziam:, ai meu Deus, agora a Maria Amélia e o Cláudio tiveram um menino todo complicado, ah agente nem vai lá, por que o que a gente vai dizer, a gente não vai lá. Quer dizer, a primeira coisa que acontece é que isola. (...) Ninguém convida a criança para nada. E aí começa a invisibilidade.

A invisibilidade vivenciada por pessoas com deficiência, é um fato que ainda precisa ser vencido em nossa sociedade, pois muitos casos de discriminação contra pessoas com deficiência e seus familiares não aconteceriam se em nossa sociedade a pessoa com deficiência fosse tratada com dignidade e respeito.

Mesmo tendo que lidar com o luto, com o isolamento de alguns membros da família e com os sofrimentos por ter um filho com deficiência, Maria Amélia narra que desde que Ricardo era bebê, sempre lutou muito para proporcionar atendimentos e tratamentos que possibilitassem uma melhor condição de vida para seu filho, desde massagens realizadas três vezes ao dia estimulando os músculos para que o ficasse em pé e conseguisse caminhar até pedir auxílio para pilotos de avião para que trouxessem, de Nova Iorque, os medicamentos utilizados para controle das crises convulsivas.

$\mathrm{O}$ fato de ter se unido a outros pais para buscar meios para auxiliar seu filho, também contribuiu para que Maria Amélia tivesse acesso a profissionais, tratamentos e atendimentos, o que possibilitou a Ricardo melhor desenvolvimento, pois como ela aponta: "[...] a APAE nasceu de uma grande angústia, a de termos de lutar pelo nosso filho deficiente mental. Só que não sabíamos de que maneira, e pouco ou nada conhecíamos dos problemas de nossos filhos." (XAVIER, 1984, p.40).

Maria Amélia, sabendo da importância de um processo de escolarização para o desenvolvimento de Ricardo, o matriculou na escola especial, o Instituto de Ortofrenia em 1963, onde permaneceu estudando meio período até 1970, quando, devido à morte de sua mãe, que cuidava dele enquanto trabalhava, o transferiu para o sistema de internato na mesma escola, na qual permanecia durante toda a 
semana, retornado aos sábados e domingos para casa. O processo de escolarização de Ricardo foi muito difícil e sofrido para Maria Amélia, que narra ter demorado a se acostumar com a ideia de deixá-lo na escola por um período e angústia maior vivenciada quando o colocou no internato. Sofrimento que se diluiu com o tempo, quando percebia a satisfação de Ricardo e sua felicidade em poder conviver com outras pessoas e realizar atividades diferentes.

Em 1978 Ricardo deixou a escola especial, sendo transferido para a Residência Aratãs, que foi uma instituição mantida pela APAE de São Paulo, para atendimento de adultos com deficiência intelectual. De acordo com Maria Amélia, era um serviço de grande importância que deixou de funcionar em 1997. Ela afirma que ficou muito abalada com o fechamento da Residência e que na época, embora sem sucesso, argumentou com a Jô Clemente que era a presidente da APAE:

No mundo todo não se fecha serviços para a família, abre-se. Não pode, se está caro, vamos ver, a APAE tem tanto conhecimento, vamos ver se consegue algum financista, uma pessoa que tenha dinheiro, ou ás vezes um parente, que queira ajudar a manter isso aqui. Não é tão difícil assim. A gente faz 'rifinha', um evento, um jantar, qualquer coisa, a gente dá um jeito, o que for preciso a gente faz, mas não fecha. Mas fecharam.

Quando passou a morar novamente na casa com seus pais, Ricardo já possuía mais de quarenta anos, Maria Amélia e seu esposo, por sua vez mais de setenta anos. Este fato exigiu da família que se reorganizasse para atender às suas necessidades, visto que eram dois idosos cuidando de uma pessoa que necessitava de grande auxílio.

\section{Ricardo envelheceste e a família idosa:}

O processo de envelhecimento das pessoas com deficiência vem sendo apresentado como uma situação que merece a atenção de toda a sociedade, visto que, por ser uma condição recente no contexto brasileiro, poucos são os atendimentos e a atenção dada a esta demanda.

Maria Amélia, em seu texto: "Tenho um filho deficiente que está envelhecendo, e agora?" (XAVIER, 2010) aponta que, de forma geral, o processo de envelhecimento é difícil para todas as pessoas, principalmente por associar-se a ideia de finitude da vida e comenta que:

Quanto a mãe de um filho com deficiência intelectual se angustia quando percebe os primeiros sinais de envelhecimento no filho amado, (que interiormente sempre considerou uma criança); esse fato, como aconteceu comigo quando subitamente um dia, no meio da minha vida corrida, vi que os lindos cabelos do Ricardo, meu filho, estavam brancos como a neve e se tornando mais frágeis e ralos, logo ele que tinha uma belíssima cabeleira! Isso me causou um susto e uma angústia profunda, pois não sei o que lhe reserva o futuro, quando não mais esteja a seu lado para lhe dar a atenção integral que todas nós, mães de filhos especiais, damos a nossos filhos com deficiências (XAVIER, 2010).

Esta questão já a preocupava em 1984, quando apresentou em seu livro suas inquietações com o envelhecimento das pessoas com deficiência e a necessidade de serem implantados serviços de atendimento às pessoas com deficiência que alcançavam a maturidade e a seus familiares. Mas, naquela época não considerava que enfrentariam a velhice juntos, pois como ela pontuou: "O que nós, pais, devemos fazer é pensar com amadurecimento em criar condições para esse período de vida de nossos filhos, quando não mais aqui estivermos para compartilhar todos os seus momentos, ou a maioria deles"

Quando Ricardo retornou para casa, Maria Amélia conta que ficou muito feliz, afinal "Lugar da gente é com a família", mas devido a sua saúde fragilizada surgiram diversos desafios, pois como o Ricardo possui dificuldades na coordenação motora e também na marcha, ele precisava de auxílio constante, visto que eles residem em um "modesto sobradinho", como ela caracteriza, que conta 
com diversos degraus, o que muito dificulta o trânsito dele dentro de casa. Ela narrou que:

O Ricardo ia numa escola da prefeitura chamada Instituto É Forte, mais eu tinha que acordar cinco e meia da manhã porque o Ricardo, na época andava, mais com dificuldade. Então ele tinha que descer da cama, tinha quer ir ao banheiro, depois eu tinha que colocar a calça dele, depois tinha isso e aquilo, ele tomava seu lanche e seus remédios. Então com muita dificuldade eu descia as escadas com o Ricardo as sete e quinze da manhã, porque as sete e meia passava aqui uma van da Atende, Mais eu tinha dito para o pessoal da Atende: Olha, quando começar a chuviscar, ou qualquer dia que chover, o Ricardo não pode ir, porque o Ricardo leva dez minutos para descer a escada.

Maria Amélia contou que seu marido sempre a ajudou, mas que, também com quase noventa anos, não dispunha de condições físicas para lidar com o filho. Narrou que no início de 2013 Ricardo teve uma infecção pulmonar grave, tendo que permanecer por quinze dias na UTI, o que desencadeou um agravamento de suas limitações motoras necessitando de auxílio para realização de todas as atividades, como ir ao banheiro, tomar banho, e não contavam com alguém para auxiliá-los, já que não possuíam condições financeiras para arcar com os custos de um funcionário. Assim, narrou que as dificuldades eram grandes, pois:

O Ricardo pesa oitenta quilos. Não tinha condição de uma coitada de uma trôpega velhinha que mesmo tendo um equilíbrio razoável para alguém da sua idade, segurar o Ricardo, por exemplo, na cadeira de banho, e se ele caísse no chão, como poderia colocar o Ricardo de pé, não podia, meu marido a mesma coisa, então resultado, não tinha condições de nós estimularmos o Ricardo, e ficava muito difícil, como que uma pessoa pode ficar deitada numa cama? A gente fazia ele sentar toda hora, porque precisava sentar, mas não ficava, não tinha nenhum interesse isso pra ele.

Pegoraro e Smeha (2013) pontuam que as perdas das capacidades físicas, sensoriais e emocionais dos pais idosos comprometem e dificultam o atendimento prestado ao filho com deficiência, uma vez que com o envelhecimento da pessoa com deficiência, aumentam as exigências e por outro lado, os pais conseguem ajudar menos. Breitenbach (2001) já afirmava que os cuidadores das pessoas com deficiência necessitam e merecem assistência e cuidados como os filhos, mas que na maior parte das vezes, estão preocupados com as finanças, com a moradia, com os problemas de saúde e continuam a cuidar, sem condições, do filho com deficiência.

Ela contou que não sabia mais como agir, quando a visitou uma amiga, assistente social, que sabendo das dificuldades enfrentadas indicou que Maria Amélia colocasse Ricardo em uma instituição que abriga pessoas com paralisia cerebral e oferece todos os atendimentos de que ele precisava. Para ela foi um choque muito grande, pois ao mesmo tempo em que sabia das dificuldades que estavam enfrentando, não queria se distanciar do filho. Disse que foi muito difícil ouvir a amiga que ponderou:

Maria Amélia, eu sei que você vai chorar muito pelo Ricardo sair daqui, porque você teve a vida inteira em volta do Ricardo, não é? Você vai ter que fazer isso, você não tem condições físicas mais de cuidar do Ricardo.

Mas, decidir sobre a institucionalização de Ricardo mobilizou toda a família e provocou grande sofrimento, sobre o qual Maria Amélia apontou:

Foi muito difícil pra mim, muito difícil enquanto mãe, o meu marido é muito apegado ao Ricardo foi muito difícil a Mina ter vindo aqui falar. Foi uma coisa muito difícil pra mim, porque eu disse: meu Deus, o que é que eu fiz da vida pra merecer de repente ter um filho como o Ricardo tão bonzinho, por que o Ricardo é uma pessoa maravilhosa, e vou ter que ficar longe do meu filhinho que é apegado a mim do jeito que ele é, como é que de repente eu vou ficar sem o Ricardo.

Breitenbach (2011) analisa que os pais idosos, não precisam apenas de momentos de alívio, ou descanso dos filhos que apresentam deficiência, mas sim que sejam disponibilizados serviços e 
atendimentos de diversas ordens, para que sejam auxiliados nos cuidados e apresenta que seria interessante disponibilizar aos pais atividades organizadas durante o dia para que a pessoa com deficiência amplie seus contatos sociais, além de receber estímulos diversos; serviços de transporte para as atividades; ajuda em casa nas tarefas domésticas, informações e orientações sobre seus direitos e opções; apoio psicológico; e que recebam cuidados adequados relacionados a saúde, a fim de que possam permanecer saudáveis.

Porém, como no Brasil os pais das pessoas com deficiência ainda não dispõem de serviços desta natureza e não restando alternativas, Maria Amélia e seus familiares decidiram levar Ricardo para a instituição.

\section{A institucionalização}

Foi com pesar que Maria Amélia recordou a data exata em que levou Ricardo para a instituição e apresentou o quanto foi difícil para eles se acostumarem com a ausência do filho. Narrou que ela e esposo visitavam a instituição duas vezes por semana e passam longos períodos com o filho.

Ela afirma que Ricardo gostava da instituição, que estava feliz, que fez muitos amigos e que um dos funcionários disse que ele era o mascote do lugar, outros ainda parabenizam Maria Amélia pela educação e carinho que o filho trata todas as pessoas. Ela narrou que

Ricardo tem uma bondade de espírito. Eu falei para o Ricardo: Ricardo você gosta do Vinícius? Ele respondeu: Ah gosto, теи amigo, meu amigo. $O$ Vinícius nem fala nada, nem estica o braço direito, o Ricardo estica o braço para ele vira com o bracinho torto pra cá e pra lá, sabe, segura ele. Por exemplo, o Ricardo é uma pessoa que se dá com todo mundo. E os enfermeiros dizem: O Ricardo é uma pessoa que colabora com a gente, não dá trabalho nenhum. [...] por exemplo, um menino estava com dificuldade, não estava querendo colocar aquele aparelho de medir pressão, e o menino mexia com o braço, não havia jeito. Ai, o Ricardo foi lá e segurou na mão do menino e falou: fica quietinho, fica quietinho, deixa o braço quietinho, não vai doer nada, precisa ver direitinho o que tem. Ai o menino ficou quieto.

Embora estivesse tranquila e satisfeita com a instituição que, segundo ela atendeu Ricardo muito bem, algumas posturas não coincidem com os conhecimentos atuais sobre as pessoas com deficiência e cita como exemplo o fato de profissionais da instituição chamarem os adultos de crianças e a forma como organizam as roupas, pois estas são de uso coletivo, impedindo que as pessoas com deficiência tenham o direito de escolher suas roupas.

De forma geral, Maria Amélia acreditava que é preciso evoluir muito no que diz respeito a atenção dada ao idoso e principalmente ao idoso com deficiência intelectual, tanto em relação a saúde, a possibilidades de relações sociais e ao lazer, pois geralmente são pessoas, que devido a grande quantidade de medicação ingerida ao longo da vida, às complicações de saúde e a maior vulnerabilidade, vivenciam a velhice antecipadamente.

Ela aponta ainda que os idosos com deficiência intelectual enfrentam a invisibilidade da sociedade, o que acarreta maiores comprometimentos e dificulta a elaboração de propostas que atendam esta população.

Em sua opinião deveriam existir mais instituições que apoiem às famílias de pessoas com deficiência em processo de envelhecimento, além de atendimentos específicos, tanto para as pessoas com deficiência, quanto para seus familiares.

Maria Amélia concluiu a entrevista apresentando quais eram, em seu ponto de vista, os maiores desafios de ser mãe de um adulto idoso com deficiência intelectual, que são o preconceito que a sociedade ainda tem para com as pessoas com deficiência, considerando-as como incapazes, a fragilidade da legislação relacionada a pessoas com deficiência em processo de envelhecimento e de atendimentos específicos. 


\section{CONSIDERAÇÕES FINAIS}

O aumento da expectativa de vida da população com deficiência intelectual tem deflagrado a necessidade da realização de pesquisas e estudos que possibilitem conhecer melhor esta população, pois se trata de um grande contingente de pessoas, que graças ao acesso a programas de saúde, a melhores condições de higiene e a mudanças nas formas de organização social, vem alcançando idades cada vez mais elevadas e que clamam por auxílio em suas diversas necessidades.

Conhecer melhor a trajetória de Maria Amélia e de seu filho possibilitou refletir sobre as diversas situações vivenciadas por pessoas idosas que são responsáveis pelos cuidados do filho com deficiência intelectual em processo de envelhecimento, além de compreender a urgência na elaboração de propostas de atendimentos que assegurem tanto às pessoas com deficiência em processo de envelhecimento como a seus pais condições dignas de vida.

Entretanto, ainda há muito a ser desvelado, é necessário analisar este fenômeno por diversos ângulos, analisá-lo sob diferentes perspectivas teórica e concepções, é necessário conhecer melhor esta população, seus anseios, suas aspirações, suas necessidades, ou seja, é necessário conhecer os aspectos relacionados a saúde, às questões sociais, emocionais de todos os envolvidos e principalmente, é necessário conhecer o Ricardo e os vários 'ricardos' que estão envelhecendo junto a seus pais idosos.

\section{AGRADECIMENTOS}

Agradecemos imensamente a disponibilidade e atenção recebida de Maria Amélia Vampré Xavier, pessoa de inestimável valor. Ela faleceu em 30 de junho de 2018 deixando importante legado para a defesa das pessoas com deficiências.

\section{REFERÊNCIAS}

ALBERTI V. Manual de história oral. 3. ed. Rio de Janeiro: FGV, 2013.

AMARAL, L. A. Conhecendo a deficiência em companhia de Hércules. São Paulo: Robe editorial, 1995.

BARBOSA, M. A. M.; CHAUD, M. N. ; GOMES, M. M. F. Vivências de Mães com um filho deficiente : um estudo fenomenológico . Acta paul. enferm. [online]. 2008, vol.21, n.1, pp. 46-52. ISSN 1.982-0194.

BARDIN, L. Análise de Conteúdo. Lisboa, Portugal: Edições 70, 1977.

BRASIL, F. R. Desenvolvimento da identidade em pessoas com deficiência mental em fase de envelhecimento. Revista científica eletrônica de Psicologia, Marília, ano I número 1, nov. 2003. Disponível em: http://faef.revista.inf.br/imagens_arquivos/arquivos_destaque/9tKVEB8M6YLykL1_2013-4-30-10-2630.pdf . Acesso em: 20 jun. 2017.

BREITENBACH, N. Paralelos em envelhecimento. 2001. Disponível em: http://www.portaldoenvelhecimento.org.br/acervo/artieop/Geral/artigo2.htm. Acesso em: 10 jun. 2017.

CLEMENTE FILHO, A. S.; GROTH, S. M.(org.) Envelhecimento e deficiência mental: uma emergência silenciosa. São Paulo: Instituto Apae, 2004. 
COSTA, L. B. B. Essas pessoas que envelhecem...saberes de adultos com deficiência intelectual. 2012 . 121f. Dissertação (Mestrado em Educação) Universidade Federal do Rio Grande do Sul. Disponível em: http://www.lume.ufrgs.br/handle/10183/61972 Acesso em 20 jun. 2017.

FLÓREZ, J. Aspectos médicos del anciano com deficiencia mental. In: GAFO, J.; AMOR, J. R.

Deficiencia mental y final de la vida. Madrid: Universidad Pontificia Comillas, 2000.

GIRARDI, M.; PORTELLA, M. R.; COLUSSI, E. L.. O envelhecimento em deficientes intelectuais.

RBCEH, Passo Fundo, v. 9, Supl. 1, p. 79-89, 2012. Disponível em:

www.upf.br/seer/index.php/rbceh/article/download/2799/pdf. Acesso em: 20 jun. 2017.

GLAT, R., et. al. O método de história de vida na pesquisa em educação especial. Revista Brasileira de Educação Especial, Marília, Mai.-Ago. 2004, v.10, n.2, p.235-250. Disponível em:

http://www.abpee.net/homepageabpee04_06/artigos_em_pdf/revista10numero2pdf/8glatetal.pdf. Acesso em: 15 abr. 2017.

JANNUZZI, G. M.; CAIADO, K. R. M. APAE: 1954 a 2011: algumas reflexões. Campinas, SP.: Autores Associados, 2013.

MAZZOTTA, M. J. S. Educação Especial no Brasil: história e políticas públicas. São Paulo: Cotez, 1996.

MARIN, M. J. S. et al. As condições de vida e saúde de pessoas acima de 50 anos com deficiência e seus cuidadores em um município paulista. Rev. bras. geriatr. gerontol. [online]. v.16, n.2, p. 365-374. 2013. Disponível em: http://www.scielo.br/pdf/rbgg/v16n2/16.pdf. Acesso em: 10 jun.2017.

MARTINS, D. V.; BARBOSA, R. S.; SILVA, A. J. B. O desafio de envelhecer com síndrome de down. Congresso internacional de envelhecimento humano: Avanços da ciência e das políticas públicas para o envelhecimento, Campina Grande PB , 2013. Disponível em http://www.editorarealize.com.br/revistas/cieh/trabalhos/Comunicacao_oral_idinscrito_2219_fd3cfca6328 935e0a423fbb942201f26.pdf. Acesso em: 20 jun. 2017.

MEIHY, J. C. S. B. Manual de história oral. São Paulo: Loyola, 2005.

MEIHY, J. C. S. B.; HOLANDA, F. História oral: como fazer, como pensar. São Paulo: Contexto: 2007.

MERLEAU-PONTY, M. Fenomenologia da Percepção. São Paulo: Martins Fontes, 1994.

PEGORARO, C.; SMEHA, L. N. A experiência da maternidade na velhice: implicações do cuidado ao filho com deficiência intelectual. Barbaroi [online]. 2013, n.39. Disponível em:

http://bases.bireme.br/cgibin/wxislind.exe/iah/online/?IsisScript=iah/iah.xis\&src=google\&base=LILACS \&lang=p\&nextAction=lnk\&exprSearch=701918\&indexSearch=ID. Acesso em 20 jul. 2017.

PESSOTTI, I. Deficiência Mental: da superstição à ciência. Marília: ABPEE, 2012.

REZENDE, A. M. Concepção fenomenológica da educação. São Paulo: Cortez: Autores Associados, 1990.

ROJAS, J. E. A. O indizível e o dizível na história oral. In: MARTINELLI, M. L. (org). Pesquisa qualitativa: um instigante desafio. São Paulo: Veras, 1999.

SCHETTERT, L. S. O deficiente mental idoso institucionalizado: reflexões sobre suas interações. 2006. 128f. Dissertação (mestrado) - Universidade de Passo Fundo. Disponível em:

http://www.dominiopublico.gov.br/download/texto/cp020133.pdf. Acesso em: 20 jun. 2017. 
SEGALLA, J. I. S. F.; SILVA, C. R.; PEDROSO, G. S. O idoso e a deficiência: um novo olhar à questão da inclusão social do idoso. In: Congresso Nacional do CONPEDI, 17, 2008, Brasília DF. Disponível em: http://www.conpedi.org.br/manaus/arquivos/anais/brasilia/06_577.pdf. Acesso em: 20 jun. 2017.

SIMSON, O. R. M.; GIGLIO, Z. G. A arte de recriar o passado: história oral e velhice bem sucedida. In:

NERI, A. L. (org.) Desenvolvimento e envelhecimento: perspectivas biológicas, psicológicas e sociológicas. 5. ed. Campinas, SP: Papirus, 2012.

SIQUEIRA, M. E. C. Envelhecer com deficiência intelectual: ouvindo a cidade e a família. 2011. 110 f. Tese (Doutorado em Educação). Universidade Estadual de Campinas. Disponível em: http://repositorio.unicamp.br/bitstream/REPOSIP/250865/1/Siqueira_MariaElianeCatundade_D.pdf . Acesso em: 20 jun. 2017.

SIQUEIRA, M. E. C.; NERI, A. L. Qualidade de vida das pessoas que envelhecem com deficiência mental. In: NERI, A. L. (Org.). Qualidade de vida na velhice. 2. ed. Campinas, SP: Alínea, 2011.

TINÓS, L. M. S. Caminhos de alunos com deficiências à educação de jovens e adultos: conhecendo e compreendendo trajetórias escolares. 2010. 125f. Tese (Doutorado em Educação Especial) Universidade Federal de São Carlos, 2010.

VALENZA, A. A.; PIRES JÚNIOR, H. O envelhecer dos indivíduos com síndrome de down. Encontro Internacional de Produção Científica Cesumar, 6, 2009. Maringá. Disponível em: http://www.cesumar.br/curtas/psicologia2008/trabalhos/O_ENVELHECER_DOS_INDIVIDUOS_COM_ SINDROME_DE_DOWN.pdf. Acesso em: 20 jun. 2017.

XAVIER, M. A. V. O outro lado do arco-íris: meu filho Ricardo. São Paulo: Diniz, 1984.

XAVIER, M. A. V. Tenho um filho deficiente que está envelhecendo, e agora? 2010. Disponível em: https://docslide.com.br/documents/tenho-um-filho-deficiente-que-esta-envelhecendo-e-agora.html. Acesso em 20 jan. 2017.

XAVIER, M. A. V. Como poder ajudar, de fato, as pessoas da família (a maioria esmagadora) mulheres eu cuidam do filho que está envelhecendo com os pais? 2014. Disponível em: apaepr.org.br/arquivo.php?arq_id=25238. Acesso em 01 jun. 2017

XAVIER, M. A. V. Enfrentando o desafio: envelhecimento e deficiência. Livro virtual, 2015. Disponível em: http://apaebrasil.org.br/arquivo.php?arq_id=27127 . Acesso em 8 jun. 2017. 